\title{
PRÁTICAS EXTENSIONISTAS A MULHERES COM VIDA MARCADA PELO USO DO CRACK: METODOLOGIAS ATIVAS E ECONOMIA SOLIDÁRIA
}

\section{OUTREACH PRACTICES FOR WOMEN ADDICTED TO CRACK: ACTIVE METHODOLOGIES AND SOLIDARITY ECONOMY}

Tainá de Jesus Alves Portela ORCID: https://orcid.org/0000-0003-1422-3240

Sibele Pontes Rocha ORCID: https://orcid.org/0000-0002-9001-7265

Maristela Inês Osawa Vasconcelos ORCID: https://orcid.org/0000-0002-1937-8850

\section{Resumo}

Trata-se de um relato de experiência referente às práticas de metodologias ativas e Economia Solidária realizadas por acadêmicos de Enfermagem em um grupo de mulheres usuárias de crack, na carga de ensino-extensão do Módulo de Práticas Interdisciplinares de Ensino, Pesquisa e Extensão I (PIEPE I), ofertado pela Universidade Estadual Vale do Acaraú, localizada em Sobral, Ceará. Os encontros foram explicitados em três categorias, denominadas Estreitando Laços para a Construção de Vínculos entre Acadêmicos, Profissionais, Familiares e Mulheres; Construindo Alicerces para a Economia Solidária: Promovendo Saúde através da Arte; e Potencialidades e Desafios de uma Experiência Comunitária: Olhar de cuidado aos que iniciam a vida e Fortalecimento do Binômio. Assim, pode-se findar o resgate do ser mulher e de sua qualidade de vida familiar, associado ao compartilhamento de experiências e enriquecimento pessoal para as integrantes do projeto e também para os acadêmicos.

Palavras-chave: Cocaína Crack; Relações Comunidade-Instituição; Relações Mãe-Filho.

Data recebimento: $26 / 06 / 2021$

Data de aceite: $22 / 10 / 2021$

\begin{abstract}
This is an experience report related to the practices of active methodologies and Solidarity Economy carried out by nursing students. It was developed with a group of women addicted to crack, in the teaching-outreach module on Interdisciplinary Teaching, Research and Outreach Practices I (PIEPE I, Brazilian acronyms), offered by the Vale do Acaraú State University, located in Sobral, Ceará. The meetings were arranged under three themes: Strengthening the Ties to forge the Bonds between Students, Professionals, Families and Women; Building Foundations for Solidarity Economy: Promoting Health through Art; and Potentials and Challenges of a Community Experience: Careful look to those who start life and Binomial Strengthening. Thus, it provides means for rescuing the woman and her family life quality as well as opportunity to share experiences for the personal enrichment of the participants and students.
\end{abstract}

Keywords: Crack Cocaine; Community-Institutional Relations; Mother-Child Relations.

\footnotetext{
* Enfermeira. Universidade Estadual Vale do Acaraú (UVA), Sobral, Ceará - Brasil. E-mail: tainadejesusalves@gmail.com

** Enfermeira. Universidade Estadual Vale do Acaraú (UVA), Sobral, Ceará - Brasil. E-mail: sibelepontes63@gmail.com

*** Professora da Universidade Estadual Vale do Acaraú (UVA), Sobral, Ceará - Brasil. E-mail: miosawa@gmail.com
} 


\section{Introdução}

Nos últimos anos, foram instituídas diversas políticas com foco no uso das drogas ilícitas pelas diferentes parcelas da população, projetos com aplicabilidade apenas na área judicial. No entanto, as discussões acerca dessa temática têm ganhado cada vez mais força em vários países do mundo, apresentando-se como um problema de saúde pública que acarreta agravos ao corpo humano, além de interferir na vida em sociedade. Assim, fundamentar parceria com o setor saúde foi algo plausível, visto que, anualmente, se protagonizam modelos de saúde que valorizam a implantação de uma atenção psicossocial como estratégia para a Redução de Danos (RD) (TEIXEIRA; ENGSTROM; RIBEIRO, 2017).

As tensões que permeiam o uso de drogas psicoativas surgem a partir de planos de cuidado que não visualizam o ser em sua completude, mas que optam por privar os usuários do convívio social. Assim, de 2011 a 2013, no Brasil, a Secretaria Nacional de Política sobre Drogas (Senad), com o apoio dos pesquisadores da Fiocruz, realizaram uma grande pesquisa sobre crack, com a finalidade de visualizar seu consumo e desafios no Brasil, sendo considerada a maior já desenvolvida sobre o tema, com um quantitativo de 25 mil pessoas, o que supera outra grande pesquisa feita na China, com 3 mil pessoas. Outrossim, o perfil de uso regular do crack é realizado por 370 mil usuários, correspondendo a $35 \%$ das pessoas que fazem uso de drogas ilícitas do país, com predomínio da classe feminina (FIOCRUZ, 2013).

A estigmatização e o desrespeito frente à saúde das mulheres usuárias de crack envolve mistificação e questões moralizantes no processo de cuidar de si e dos filhos, visto que o olhar da sociedade é voltado para a substância ilícita, sem considerar as vulnerabilidades e o comtexto de vida delas. Assim, é essencial enfatizar a importância da implantação de estratégias de cuidado individuais e grupais em busca de sanar a carga de preconceito vivenciada diariamente, principalmente ao envolver a maternidade e o aspecto sociocultural, a fim de contemplar as especificidades da mulher com eficaz intervenção no crack (CAMARGO et al., 2018).

De acordo com Marques et al. (2012), recém-nascidos de usuárias de crack estão sempre em estado de alerta, com intensa sugação, irritabilidade, além de agravos no sistema muscular e coluna vertebral, enquanto as crianças com mais de 10 anos expostas à droga por via transplacentária na gestação têm retrocesso do processo de desenvolvimento, o que determina que a contaminação tem efeito prolongado pós-período puerperal e ao decorrer dos anos.

Nessa perspectiva, os serviços de apoio psicossocial ao binômio mãe-filho com histórico de uso de crack e/ou outras drogas durante a gestação precisam trabalhar com ênfase na reinserção desse público na sociedade. Diante disso, uma das propostas às instituições que acolhem mães e gestantes em contextos de drogas é a elaboração de oficinas de produção, objetivando a Economia Solidária (ES), tendo em vista que a ES é uma alternativa às relações sociais de produções capitalistas, considerando, ainda, as transformações no final do século XX, contexto histórico e social da ES (GOLÇALVES; SOBRINHO, 2011). 
No tocante à inserção da ES no contexto da promoção de saúde de mulheres usuárias de crack, a extensão universitária é uma ferramenta imprescindível de transformação e compreensão das vulnerabilidades vivenciadas por esse público e seus familiares, sendo essencial interligá-la à pesquisa, para que esta seja potencializada. Introduzir esse pilar à matriz curricular da graduação em saúde juntamente com o ensino permite a integralização do cuidado e uma transformação social oportunizada pela instituição, por meio do tripé ensino, pesquisa e extensão de forma indissociável (ROCHA et al., 2019).

Diante de tal temática e das necessidades de intervenção, apresenta-se a prática educativa, com o objetivo de unir ensino e prática para organizar a vida em sociedade e reinserir as mulheres nas diversas formas de relacionamento social. O intuito é de gerar estímulos e subsídios para demais discussões e ações educativas no âmbito do enfrentamento do uso de drogas, como o crack, dentro dos contextos familiares, e a inclusão no mercado de trabalho/ sociedade.

Este estudo tem por objetivo detalhar ações de economia solidária e cuidado realizadas em uma instituição de apoio psicossocial, com enfoque na mudança de vida da díade mãefilho, em meio ao tratamento e reabilitação do consumo de crack.

\section{Metodologia}

Trata-se de um relato de experiência que busca descrever a caracterização de um fenômeno em uma parcela da população. Segundo Cavalcante e Lima (2012), os relatos de experiência são uma ferramenta de pesquisa descritiva que apresentam uma reflexão sobre uma ação ou conjunto de ações de uma situação vivenciada de interesse da comunidade científica.

O foco do estudo é inserir práticas de metodologias ativas e Educação Solidária em um grupo social, por meio da ação de acadêmicos de enfermagem do quarto semestre, na carga de ensino-extensão do Módulo de Práticas Interdisciplinares de Ensino, Pesquisa e Extensão I (PIEPE I) ofertado pela Universidade Estadual Vale do Acaraú (UVA), em Sobral, Ceará.

Nesse caso, o PIEPE I tem como cenário uma instituição de apoio psicossocial com ênfase na abordagem grupal, envolvendo o binômio mãe-filho, localizado em um município no noroeste do estado do Ceará. A amostra abrange as mães acolhidas pelo Projeto e que participaram ativamente das ações realizadas durante o período de agosto a outubro de 2017.

A Universidade propicia ao futuro enfermeiro, ao longo dos semestres de graduação, a oportunidade de estar em contato integral com a assistência, nos seus três níveis: Atenção Primária, Secundária e Terciária. Tal módulo é uma estratégia de curricularização da extensão universitária da Enfermagem, do quarto ao sétimo semestre (PIEPE I, II, III e IV), o qual permite abordar diferentes públicos etários: adolescentes, crianças e idosos, até a elaboração de conteúdos científicos com fins de publicação sobre um dos PIEPES realizados. 
Diante da nuance, é válido pontuar que o atendimento à gestante usuária de crack vem sendo realizado de forma diferenciada desde 2010, por meio de um programa específico vinculado à Estratégia Trevo de Quatro Folhas, com ações para reduzir a morbimortalidade infantil e de danos associados ao feto. Criado em 26 de março de 2005, sem fins lucrativos e de caráter filantrópico, o projeto visa apoiar a mãe e valorizar a vida, fortalecendo a qualidade da assistência no pré-natal, parto, puerpério, desenvolvimento da criança nos dois primeiros anos de vida e no incentivo ao aleitamento materno exclusivo nos seis primeiros meses.

Durante a realização do trabalho, foram abordadas cerca de 40 crianças menores de 2 anos e suas mães usuárias de crack do município, além de 25 gestantes usuárias de crack identificadas pela Estratégia Saúde da Família e encaminhadas à Estratégia Trevo de Quatro Folhas. Logo, urgiu-se a realização de oficinas que possibilitassem gerar meios de retorno econômico para as participantes obterem um novo meio de vida, já que, devido à falta de verba disponibilizada pelo Governo/Estado, foram-se encerradas as atividades que envolviam a venda/fabricação de biscoitos caseiros.

Mediante tal contextualização, os momentos foram semanais resultando em 12 encontros práticos, com duração média de 4 horas, pautados na abordagem de temáticas solicitadas pelas participantes, serviço ou diante da situação emergencial demonstrada.

\section{Resultados e discussão}

Os resultados deste estudo são apresentados e discutidos em tópicos que pautam a importância da extensão para o contato permanente e criação de laços das participantes do projeto com os acadêmicos, assim, tal aproximação estabeleceu pontos de partida para a elaboração e o êxito das práticas educativas frente à intervenção e inclusão social das mulheres que emfrentam problemas relacionados ao uso abusivo do crack, gerador de instabilidades pessoais, econômicas, familiares e emocionais.

O encontro inicial oportunizou uma imersão no Projeto e ambiente de práticas por meio da apresentação, para os presentes, e diálogo com a coordenadora, assistente social e pedagoga do serviço, aliados à observação de características das participantes e seus territórios de inserção.

Os momentos vivenciados e os dados coletados foram possíveis através de oficinas de produção e outras dinâmicas com diferentes temáticas de conhecimento, aprendizagem, diálogo e incentivo da economia solidária. Os Quadros 1, 2 e 3 apresentam um resumo sobre os encontros realizados, relacionando-se suas temáticas, metodologias, materiais, objetivos e participantes.

É válido ressaltar que as ações mencionadas posteriormente foram desenvolvidas pelos acadêmicos de Enfermagem, com o apoio da enfermeira coordenadora, assistente social e pedagoga que compunham o quadro de profissionais do serviço no momento dos encontros. 
Quadro 1 - Síntese dos Encontros 1, 2, 3, 4, 5, 7, 8 e 11 relacionados à vinculação de laços com as participantes do projeto, 2020.

\begin{tabular}{|c|c|c|c|c|c|}
\hline ENCONTRO & TEMÁTICA & METODOLOGIA & MATERIAIS & OBJETIVOS & PARTICIPANTES \\
\hline $1^{\circ}$ Encontro & $\begin{array}{l}\text { Cuidar de quem } \\
\text { cuida: novo } \\
\text { projeto familiar, } \\
\text { perspectivas e } \\
\text { superação de } \\
\text { obstáculos }\end{array}$ & \begin{tabular}{|l|} 
Caminho do Cui- \\
dado Familiar. \\
Compartilhamento \\
de histórias de vida. \\
Desenhos e frases \\
de presente, pas- \\
sado e futuro. \\
Varal 'Se eu \\
Sonho eu Posso \\
Conquistar'.
\end{tabular} & $\begin{array}{l}\text { Óleos, hidratante, } \\
\text { ambiente climati- } \\
\text { zado, TNT, per- } \\
\text { fume, espelho. } \\
\text { Som e música. } \\
\text { Papéis, canetas, } \\
\text { lápis de cor, corda, } \\
\text { fita adesiva e cola. }\end{array}$ & $\begin{array}{l}\text { Possibilitar o } \\
\text { diálogo familiar e } \\
\text { a construção de } \\
\text { novos projetos de } \\
\text { vida familiar. }\end{array}$ & $\begin{array}{l}\text { Familiares das } \\
\text { participantes do } \\
\text { projeto presentes } \\
\text { na reunião mensal } \\
\text { destinada a eles. }\end{array}$ \\
\hline $2^{\circ}$ Encontro & $\begin{array}{l}\text { Abordando o } \\
\text { Suicídio }\end{array}$ & $\begin{array}{l}\text { Relato de } \\
\text { tentativas/ } \\
\text { pensamentos } \\
\text { suicidas. }\end{array}$ & $\begin{array}{l}\text { EVA, papel, } \\
\text { caneta, lápis, fitas } \\
\text { adesivas e } \\
\text { tesouras. }\end{array}$ & $\begin{array}{l}\text { Educar sobre a } \\
\text { Semana do } \\
\text { suicídio. }\end{array}$ & $\begin{array}{l}\text { Participantes do } \\
\text { projeto. }\end{array}$ \\
\hline $3^{\circ}$ Encontro & $\begin{array}{l}\text { Brincando com } \\
\text { quem precisa viver } \\
\text { a infância. }\end{array}$ & $\begin{array}{l}\text { Dinamização com } \\
\text { as crianças para } \\
\text { vinculação. }\end{array}$ & Brinquedos. & $\begin{array}{l}\text { Interagir com o } \\
\text { público infantil do } \\
\text { Projeto. }\end{array}$ & $\begin{array}{l}\text { Filhos das } \\
\text { participantes. }\end{array}$ \\
\hline $4^{\circ}$ Encontro & $\begin{array}{l}\text { De Encontro ao } \\
\text { Território: Visitas } \\
\text { Domiciliares no } \\
\text { conhecimento da } \\
\text { realidade do } \\
\text { próximo. }\end{array}$ & $\begin{array}{l}\text { Visita Domiciliar } \\
\text { Conversa com } \\
\text { familiares. } \\
\text { Entrega de cestas } \\
\text { básicas. }\end{array}$ & $\begin{array}{l}\text { Carro, cestas e } \\
\text { alimentos. }\end{array}$ & $\begin{array}{l}\text { Conhecer o terri- } \\
\text { tório de inserção } \\
\text { familiar e os } \\
\text { contextos de } \\
\text { vulnerabilidades } \\
\text { em saúde. }\end{array}$ & $\begin{array}{l}\text { Familiares das } \\
\text { participantes do } \\
\text { projeto. }\end{array}$ \\
\hline $5^{\circ}$ Encontro & $\begin{array}{l}\text { A Cultura de Paz } \\
\text { na Abordagem da } \\
\text { Violência }\end{array}$ & $\begin{array}{l}\text { Rodas de debate } \\
\text { Escuta qualificada } \\
\text { Diálogo sobre de- } \\
\text { safios da educação }\end{array}$ & $\begin{array}{l}\text { Data show, mesa e } \\
\text { filmes. }\end{array}$ & $\begin{array}{l}\text { Abordar a } \\
\text { violência familiar } \\
\text { e à mulher. }\end{array}$ & $\begin{array}{l}\text { Participantes ads- } \\
\text { critos do projeto. }\end{array}$ \\
\hline $7^{\circ}$ Encontro & $\begin{array}{l}\text { Pré-conceito } \\
\text { versus Fofoca: o } \\
\text { que fazer }\end{array}$ & $\begin{array}{l}\text { Dinâmica Telefone } \\
\text { sem fio. } \\
\text { Bate-papo } \\
\text { Construir frases. }\end{array}$ & Tarjetas e imagens & $\begin{array}{l}\text { Debater o } \\
\text { impacto/desafio da } \\
\text { comunicação na } \\
\text { atualidade }\end{array}$ & $\begin{array}{l}\text { Participantes ads- } \\
\text { critos do projeto. }\end{array}$ \\
\hline $8^{\circ}$ Encontro & $\begin{array}{l}\text { As facetas da } \\
\text { Integração/ } \\
\text { Negação }\end{array}$ & $\begin{array}{l}\text { Correio Integrativo } \\
\text { Mural da negação }\end{array}$ & $\begin{array}{l}\text { Papel, caneta e } \\
\text { lápis de cor. }\end{array}$ & $\begin{array}{l}\text { Trabalhar a } \\
\text { negação no uso do } \\
\text { crack }\end{array}$ & $\begin{array}{l}\text { Participantes ads- } \\
\text { critos do projeto. }\end{array}$ \\
\hline $11^{\circ}$ Encontro & $\begin{array}{l}\text { Trilha da Equidade } \\
\text { de Gênero }\end{array}$ & $\begin{array}{l}\text { Diferença de } \\
\text { gênero imposto } \\
\text { pela sociedade. } \\
\text { Seção histórica da } \\
\text { mulher na sociedade. } \\
\text { Árvore e trilha dos } \\
\text { gêneros }\end{array}$ & $\begin{array}{l}\text { Tarjetas com } \\
\text { etapas da história } \\
\text { da mulher na } \\
\text { sociedade. } \\
\text { Incentivo da } \\
\text { Independência } \\
\text { Financeira. }\end{array}$ & $\begin{array}{l}\text { Visionar as } \\
\text { desigualdades } \\
\text { enfrentadas pela } \\
\text { mulher ao longo } \\
\text { da história e os } \\
\text { desafios de gênero } \\
\text { no mercado. }\end{array}$ & $\begin{array}{l}\text { Participantes ads- } \\
\text { critos do projeto. }\end{array}$ \\
\hline
\end{tabular}

Fonte: Elaborado pelos autores 
Quadro 2 - Síntese dos Encontros 6, 9 e 10 relacionados à implantação da economia solidária com as participantes do projeto, 2020.

\begin{tabular}{|l|l|l|l|l|l|}
\hline ENCONTRO & \multicolumn{1}{|c|}{ TEMÁTICA } & METODOLOGIA & \multicolumn{1}{|c|}{ MATERIAIS } & \multicolumn{1}{|c|}{ OBJETIVOS } & PARTICIPANTES \\
\hline $6^{\circ}$ Encontro & $\begin{array}{l}\text { Laços, Sonhos e } \\
\text { Fitas. }\end{array}$ & $\begin{array}{l}\text { Oficina: Artesanato } \\
\text { e decoração de } \\
\text { laços } \\
\text { Oportunidade de } \\
\text { vínculo e conversa } \\
\text { aprofundada. }\end{array}$ & $\begin{array}{l}\text { Mesas, retalhos de } \\
\text { tecidos, fitas, } \\
\text { presilhas, cola, } \\
\text { tesouras e pérolas. }\end{array}$ & $\begin{array}{l}\text { Instituir a } \\
\text { Economia solidária }\end{array}$ & $\begin{array}{l}\text { Participantes ads- } \\
\text { critos do projeto. }\end{array}$ \\
\hline $9^{\circ}$ Encontro & $\begin{array}{l}\text { Eu pinto e faço } \\
\text { Arte. }\end{array}$ & $\begin{array}{l}\text { Comunicação } \\
\text { visual e verbal } \\
\text { para Prática } \\
\text { educativa. } \\
\text { Oficina: } \\
\text { Artesanato } \\
\text { Confecção de } \\
\text { panos de prato. }\end{array}$ & $\begin{array}{l}\text { Tintas, pincéis, } \\
\text { tecidos, formas de } \\
\text { desenhos, cola } \\
\text { quente, purpurina e } \\
\text { apliques. }\end{array}$ & $\begin{array}{l}\text { Instituir a } \\
\text { Economia solidária }\end{array}$ & $\begin{array}{l}\text { Participantes ads- } \\
\text { critos do projeto. }\end{array}$ \\
\hline $10^{\circ}$ Encontro & $\begin{array}{l}\text { Rabiscos do } \\
\text { Amanhã }\end{array}$ & $\begin{array}{l}\text { Oficina: } \\
\text { Artesanato } \\
\text { Confecção de } \\
\text { canetas }\end{array}$ & $\begin{array}{l}\text { Canetas, EVA, } \\
\text { pola quente e } \\
\text { pérolas }\end{array}$ & $\begin{array}{l}\text { Instituir a } \\
\text { Economia solidária }\end{array}$ & $\begin{array}{l}\text { Participantes ads- } \\
\text { critos do projeto. }\end{array}$ \\
\hline
\end{tabular}

Fonte: Elaborado pelos autores

Quadro 3 - Síntese do Encontro 12, relacionado à experiência comunitária de cuidado e fortalecimento do binômio com as participantes do projeto, 2020.

\begin{tabular}{|l|l|l|l|l|l|}
\hline ENCONTRO & \multicolumn{1}{|c|}{ TEMÁTICA } & METODOLOGIA & \multicolumn{1}{|c|}{ MATERIAIS } & \multicolumn{1}{c|}{ OBJETIVOS } & PARTICIPANTES \\
\hline $12^{\circ}$ Encontro & $\begin{array}{l}\text { Olhar de cuidado a } \\
\text { vida e fortaleci- } \\
\text { mento do binômio: } \\
\text { Dia das Crianças/ } \\
\text { despedida }\end{array}$ & $\begin{array}{l}\text { Brincadeiras. } \\
\text { Momento de } \\
\text { cuidado do filho. } \\
\text { Diálogos de } \\
\text { agradecimento }\end{array}$ & $\begin{array}{l}\text { Mesas, alimentos, } \\
\text { toalhas, cadeiras, } \\
\text { som, música, bola } \\
\text { e lembrancinhas. }\end{array}$ & $\begin{array}{l}\text { Integrar mães e } \\
\text { filhos em atividades } \\
\text { de lazer e estreita- } \\
\text { mento de vínculos. }\end{array}$ & $\begin{array}{l}\text { Participantes e } \\
\text { filhos adscritos do } \\
\text { projeto. }\end{array}$ \\
\hline
\end{tabular}

Fonte: Elaborado pelos autores 


\section{Estreitando laços para a construção de vínculos entre acadêmicos, profissionais, familiares e mulheres}

Os momentos foram ministrados através de ações mediadas por oficinas e rodas de conversa, para início do ciclo de recepção ao serviço e edificação de um vínculo inicial com o objetivo do projeto, que é fornecer subsídios de reintegrar as participantes em um bom convívio social, permitindo o estreitamento de relações com filhos, pais e maridos.

Todos os meses o projeto realiza uma reunião mensal com a família das integrantes para conversa, escuta e repasse da evolução/cooperação delas. Portanto, foi proposto o primeiro encontro prático, iniciado com a ação "Cuidar de quem cuida: um gesto de agradecimento e amor", através da elaboração do "Caminho do Conforto" com os familiares para que fossem trabalhados a base e o alicerce da vida das integrantes, pois, para a mudança de vida das mulheres, é ideal conhecer as causas de propensão ao uso de drogas, os motivos biopsicossociais pelos quais elas se inseriram nesse meio e os fatores que influenciaram a decadência do ambiente familiar.

De início, houve apresentação dos facilitadores e a explicação sobre o momento, fundamental para a adesão, participação das ações e melhoria no âmbito biopsicosocioespiritual. Logo após, cada familiar foi vendado para adentrar à sala, que estava decorada com frases e o chão preenchido de TNT, para servir de caminho para o conforto, no qual eles, em todo o percurso, foram afagados com palavras de carinho e incentivo, além de massagem. No final da travessia, eles teriam que adivinhar quem era a pessoa que necessitava da atenção e cuidado deles, sendo revelado, com o espelho e a retirada das vendas, que eram eles próprios os necessitantes do olhar de amor. Ao longo do caminho, os que haviam participado também colaboraram com a transmissão do amor e cuidado aos próximos que participavam.

No tocante ao grupo familiar, enquanto momento de incentivo ao diálogo, é possível acessar os sentimentos produzidos a partir da ótica dos próprios sujeitos. Nessa aproximação feita ao grupo, a interação entre os participantes permitiu não apenas a emergência de impressões, opiniões e sentimentos entre os familiares, como também o confronto entre diferentes perspectivas. Nesse sentido, o diálogo estabelecido entre as famílias se configurou como uma relação face a face, num contexto no qual cada familiar teve um posicionamento singular que complementou e interferiu nas formas de significar a sua realidade e a dos outros (LACCHINI, 2014).

Para o encerramento do dia, a ação "Compartilhar a vida: Construção de um novo projeto familiar e Varal de perspectivas e superação de obstáculos" constituiu uma interação por meio da contagem de histórias de superação, com registro de frases e desenhos que demonstram o passado, presente e como desejavam ser o futuro do convívio entre filhos e netos, o que almejou a construção de um novo projeto familiar. Momentos emocionantes de conhecimento mútuo dos sofrimentos, aconselhamento e alívio ao desabafar angústias foram pontuados. A elaboração de um material de perspectivas e superação de obstáculos proporcionou lembranças da terapia de comunicação e da ajuda mútua entre as famílias. 
A “Abordagem sobre Suicídio" constituiu o segundo encontro, o qual possibilitou o conhecimento dos anseios que geram traumas nas mulheres. Conseguir o relato das tentativas/ pensamentos suicidas foi uma experiência rica de mudança de pensamentos, entendimento da gravidade e amor pela vida. Expor esse turbilhão de sensações e convertê-las na construção de artefatos permitiu contornar a negatividade e dor que as lembranças causavam nelas.

É importante evidenciar o crack e seus efeitos no contexto familiar composto por comflitos interpessoais. O rompimento de vínculos afetivos acentua o sofrimento psíquico, gerando situações trágicas como as tentativas de suicídio, repercutindo no âmbito dos componentes familiares e sociais, trazendo questionamentos e reflexões sobre as suscetibilidades das experiências femininas relativas à droga (FERTIG et al., 2016).

O terceiro encontro foi denominado 'Brincando com quem necessita Viver a Infância'. Nesse momento, estabeleceu-se uma ponte de confiança e cuidado para os filhos das integrantes do projeto, de forma a favorecer o amor e a empatia, para entender e resgatar as crianças da exclusão social e futuro embotamento de sentimentos. Reviver a infância é empoderar as crianças como donas de uma fase de brincadeiras e diversão, de alegrias e esperança nos sonhos.

Sendo assim, urge-se um acompanhamento dessas crianças, a fim de diagnosticar antecipadamente suas necessidades sociais e fincar pontos de apoio de sensibilização na família, em prol de implementar um plano de cuidados eficaz que conecte a criança aos serviços de saúde, num trabalho interdisciplinar e intersetorial (CAMARGO et al., 2019).

O quarto encontro, denominado "De Encontro ao Território: Visitas Domiciliares no conhecimento da realidade do próximo", proporciona esse cuidado integral, já que se oportuniza entender o ambiente em que residem essas mulheres e, assim, estabelecer os fatores ou principais determinantes da vulnerabilidade social delas, desvendando o que implicou no consumo do crack e de que maneira isso afeta o crescimento e desenvolvimento efetivo das crianças.

A distribuição de cestas básicas possibilita a tentativa de recuperar mães que abandonaram o projeto, além de ser um seguimento da atenção familiar, com vistas à reabilitação das mulheres e sua inserção no mercado de trabalho, com carteira assinada. Buscar um conhecimento acerca da vivência das famílias de usuários de crack implicou também desvelar um mundo, a partir de quem se relaciona cotidianamente. Lacchini (2014) enfatiza a necessidade de ampliar a compreensão do tema e de produzir conhecimento, em especial para remodelar a enfermagem sobre a desmistificação, o acolhimento, o cuidado e a prevenção aos quais essas famílias e usuários estão expostos.

Segundo dados do estudo sobre família e atenção psicossocial, os familiares enfrentam desafios ao terem um ente imerso no mundo das drogas, como a busca por melhor convivência, a sobrecarga familiar e o desejo de ajudar seu membro com necessidades decorrentes do uso do álcool e outras drogas. Assim, diante de tais metodologias aplicadas, a atuação da família no processo de cuidado tem sua importância, garantindo melhorias no apoio e suporte, 
além de favorecer a adesão ao tratamento e a redução de internações prolongadas (BELLOTI; FRAGA; BELOTTI, 2017).

Diante disso, é essencial o investimento em estratégias de cuidado, de forma permanente, com o enfoque no manejo das usuárias de crack e de suas demandas familiares, uma vez que a inserção da família pode ser benéfica ao processo de cuidado, sendo agente contribuinte para uma melhor resolutividade dos casos, não negligenciando a necessidade de cuidado da família.

No encontro cinco "A Cultura de Paz na Abordagem da Violência", foram expostos trechos do filme Escritores da Liberdade e uma roda de debate sobre as caras da violência no cenário atual. Além disso, conversou-se sobre a dificuldade da educação escolar e familiar frente à rebeldia dos filhos, situações de bullying, diferenças socioeconômicas e difículdades de aceitação do histórico das mães pelos filhos mais velhos. Os frutos foram a possibilidade de instaurar a troca de experiências nunca antes mencionadas, deixando transparente a integração e proximidade alcançada pelos acadêmicos no contexto familiar das participantes.

O "Pré-conceito versus Fofoca... o que fazer?" foi o sétimo encontro, no qual se instituiu a dinâmica do telefone sem fio, em que uma frase fora mencionada e o foco era descobrir qual mensagem final seria repassada. Em seguida, foram distribuídas tarjetas para que as mulheres construíssem frases com a inclusão de tais palavras: preconceito, família, respeito, esperança e mudança. Percebeu-se que muitas não sabiam escrever, então os acadêmicos transcreveram o que era dito pelas mulheres. A percepção de quanto uma fala malintencionada pode afetar as boas relações e distorcer a imagem de uma pessoa através do preconceito é algo enraizado no cotidiano e vivenciado por elas devido ao consumo de drogas.

O oitavo encontro, “As Facetas da Integração e Negação", estruturou-se a tecnologia Correio Integrativo, com o objetivo de escrever, em um pedaço de papel, as características mais especiais que a pessoa que estava à frente possuía e inseri-las no envelope que tinha o nome da pessoa. No fim, cada uma pôde ler suas qualidades e escolher uma plaquinha de emoticon que representasse o seu estado de espírito naquele momento. Os frutos foram a felicidade e a descoberta de qualidades nunca antes reparadas, instituindo o amor-próprio e o autocuidado.

O décimo primeiro encontro, intitulado "Trilha da Equidade de Gênero", contou com encenações sobre situações vivenciadas na sociedade relacionadas à imposição do gênero masculino sobre o feminino, discriminações, disparidades em salários e violência doméstica. Conseguinte, construiu-se a Árvore dos gêneros com palavras que representassem igualdade, conquistas, libertações e disparidades do dia a dia, o que resultou em interiorização, reflexão e uma roda de debate rica.

Esses encontros ministrados foram de grande valia para iniciar a transformação das mulheres que participam frequentemente das atividades estabelecidas. Ao facilitar as oficinas de forma dinâmica, abordando o lado psicossocial, e ao perceber o interesse, animação e presença ativa das integrantes do projeto, o espírito de cuidar e prestar serviços à comunidade foi alavancado nos acadêmicos, o que intensificou a vontade de propagar uma nova visão de 
vida para elas. O trabalho realizado pode ser invisível para os órgãos governamentais, no entanto, para a população local, torna-se o diferencial no cuidado das vidas e famílias das usuárias que participam do projeto (CAMARGO et al., 2019).

Uma sociedade patriarcal estigmatiza a mulher, sua capacidade de ser independente e chefe do lar, principalmente se ela for uma usuária de drogas, pois as distinções sociais e os estereótipos são detentores de desigualdade social, a qual não propicia a reinserção da mulher na sociedade, tampouco o entendimento sobre sua representação. Essas concepções interferem diretamente no cuidado e autoestima, na adesão por uma vida mais saudável e na intenção de transformar a vida em algo leve, permeada pelo empoderamento e a geração de recursos próprios. A identidade é fragilizada pela opinião pública e na maneira como essas mulheres são acolhidas pela sociedade. $\mathrm{O}$ autoconceito é facilmente abalado e a promoção das potencialidades para uma melhor qualidade de vida é papel dos serviços de apoio (SILVA; PEREIRA; PENNA, 2018).

\section{Construindo alicerces para a Economia Solidária: promovendo saúde através da arte}

As ferramentas da ES por meio de oficinas são fundamentadas pelo setor saúde, estabelecendo-se como potencializador de um ambiente de cuidado e de geração de renda, configurando um produtor de capital, com o fim de potencializar o protagonismo, a autonomia e a inclusão social das mulheres. A arteterapia embasada nos trabalhos manuais permite a autoexpressão, constituindo um primeiro passo para a sobriedade e a expressão de sentimentos, mitigando sintomas e melhorando a inter-relação entre a saúde e o social (ALVAREZ; NEVES; SILVA, 2017; MAZARO; MATZUKURA; LUSSI, 2020).

A Oficina de Artesanato "Laços, Sonhos e Fitas" foi a pioneira dentre muitas que serão listadas. O momento foi alicerçado, primeiramente, com a busca de informações sobre os melhores modelos que permitiriam uma aprendizagem fácil e rápida e que, futuramente, gerariam continuidade do trabalho sem grandes obstáculos, de modo que a proposta foi lançada e recebida com entusiasmo pelas integrantes.

Em uma sala, foram dispostas mesas e cada acadêmico se responsabilizou por duas participantes para as devidas orientações e dúvidas. Primeiramente, foram fornecidos os retalhos de tecidos e demais materiais de confecção, com passo a passo de como se dariam as dobraduras e colagens, atentando que a decoração seria a cargo de cada uma das mães, comforme suas ideias e criatividade, sempre focando no artesanato como futuro retorno financeiro para colaborar no custeio de vida e renda familiar.

Os frutos de tal encontro encontram-se na elaboração de mais de 25 tipos diferentes de laços, os quais as integrantes relataram ser uma forma eficiente de renda. Ainda diante da empolgação, propuseram variadas formas de venda e uso criativo, como transformação em 
presilhas, arcos para o cabelo, acessórios para cintos ou até mesmo broches. Nos demais dias, afirmaram conseguir retorno satisfatório e que as pessoas que aderiram ao produto fizeram novas encomendas e elogiaram a qualidade dos laços.

A Oficina "Eu pinto e Faço Arte" surgiu voltada para a produção de panos de prato. A atividade desenvolveu-se em três etapas: a primeira voltada para instruções de técnicas de pintura e de decoração; a segunda com o estímulo da criatividade; e a terceira compôs-se de um feedback das integrantes referente à oficina realizada. Durante a oficina, as integrantes mostraram-se participativas e empenhadas na produção dos artigos, ademais, proporcionou interação entre o grupo e os facilitadores, aumentando, assim, o vínculo e a possibilidade de protagonismo social das participantes.

Ao final, observou-se que algumas integrantes apresentavam maior afinidade com a arte de pintura, descobrindo dons ao se identificarem com uma atividade que pode torná-las ativas no mercado de trabalho, proporcionando outro sentido à vida dos filhos.

A oficina de confecção de canetas ornamentadas "Rabiscos do Amanhã" constituiuse de um momento produtivo, que incentivou a imaginação e demandou atenção redobrada das integrantes para aprendizagem de como iniciar o modelo para instigar a geração de novos. $\mathrm{O}$ ambiente de acolhimento proporcionou uma participação ativa e interessada do conjunto, pois, por meio do exemplo padrão, deu-se lugar a novas formas e ideias, integrando as mães em um único foco e meta, impulsionadas pelo interesse da implementação de uma renda extra.

O conteúdo das três oficinas ministradas e especificadas neste artigo teve como tema norteador a economia solidária. Proveniente da década de 1990, a ES é um fenômeno que se difundiu largamente pelo país e tem por objetivo servir como incentivo à organização dos chamados empreendimentos econômicos solidários (MATSUKURA; LUSSI, 2020).

Assim, foi abordado como o retorno financeiro torna-se alternativa inovadora, reconhecida pelas próprias integrantes, para a geração de trabalho e inclusão social, agindo como forma de uma corrente do bem, que integra quem produz, quem vende, quem ensina e quem compra. Isso gera, por conseguinte, uma luta por emancipação e empoderamento nas dimensões econômicas, por meio da cooperação, cultural na reutilização de materiais/ propagação de um novo meio de renda; e política para o desenvolvimento de um trabalho autônomo, que cresce incessantemente no mundo globalizado e serve como um meio extra para assegurar a vida das famílias envolvidas (VOLZ et al., 2015).

A oportunidade de reconhecer o desempenho das mães como 'oficineiras', mesmo após o término das atividades, foi emocionante, por se poder presenciar que as participantes seguiram adiante a ideia da ajuda familiar e o empenho em aderir às ações como hobbie. Relatou-se ser maneiras de terapia e relaxamento, além da visão fixa e concisa da meta dos lucros serem revertidos para o cuidado e crescimento dos filhos, o que colaborou para a redução do consumo de drogas, no sentido de ajudar a preencher o tempo ocioso e as aflições 
da mente, oportunizando as mães a serem protagonistas do mundo de trabalho de forma ética e política (GALVES et al., 2016).

A escolha estratégica da reforma psiquiátrica brasileira, pelo modelo da reabilitação psicossocial. no qual o cuidado está centrado no sujeito compreendido enquanto cidadão de direitos, reforça a importância da temática do direito ao trabalho enquanto eixo orientador da vida. A economia solidária é uma resposta das populações pobres e sua inserção frente à estagnação financeira ganhou destaque no Brasil em 1990, pelas lutas populares por emancipação, assim constitui-se como dispositivo essencial para a saúde mental, a fim de socializar e buscar direitos (PINHO et al., 2014; MAZARO; MATSUKURA; LUSSI, 2020).

Viabilizar e garantir espaços de diálogo, de horizontalidade das relações e de tomadas de decisões coletivas que concretizam o empoderamento, o exercício da autogestão, estimulam a solidariedade e a união entre as oficinas, práticas que vão ao encontro dos princípios da economia solidária. Essa experiência é relevante para ser compartilhada e discutida, pois a implementação e sustentação desses espaços produzem cidadania (GALVES et al., 2016).

\section{Potencialidades e desafios de uma experiência comunitária: olhar de cuidado aos que iniciam a vida e fortalecimento do binômio}

Uma das maiores potencialidades aos acadêmicos facilitadores foi a interação e geração de vínculos, que contribuíram significativamente para despertar a criatividade e o desejo das mulheres em se envolver com o protagonismo social, além da possibilidade de observar o quanto o potencial de um grupo tem força para incitar a transformação de saberes e práticas, por meio do oferecimento de informações, coesão do grupo, desenvolvimento de técnicas de socialização e aprendizagem interpessoal.

As oficinas de trabalho surgiram como uma nova oportunidade para as usuárias, tendo em vista que, ao investir em novos ambientes, aspectos positivos podem ser observados na vida familiar. Quando há uma interiorização das mulheres, suas experiências têm papel de terapia e chance de articulação com o social, pois um dos desafios é o acesso a uma vida produtiva e sua reabilitação psicossocial, antes não vivenciadas. Inserir a qualidade de vida e a inclusão social permite a transposição de barreiras e edifica uma nova maneira de viver e se relacionar (LUSSI; MATSUKURA; HAHN, 2011).

A despedida foi estruturada com parte da renda arrecadada com a venda dos produtos confeccionados ao longo da imersão, que possibilitou um estreitamento dos laços das mães com seus filhos, na interação e brincadeiras. O sentimento de saudade ficou visível, com a gratidão pelo aprimoramento e expansão das ideias criativas das mulheres, que confeccionaram um novo estilo de vida. As participantes acreditam que podem compartilhar o conhecimento adquirido com outras mulheres da comunidade e com sua família, constituindo meio de base 
da incorporação de padrões de comportamento, valores morais, sociais, éticos e espirituais, nos quais os saberes formados no grupo incorporam novos pensamentos, conhecimentos e atos.

Os desafios diante da aplicação das ações são as desavenças e os desentendimentos existentes entre as participantes, assim como o competitivismo exacerbado durante as dinâmicas. Por isso, no final de cada atividade, foi discutida uma visão geral sobre o momento, frisando-se que em nenhum deles haverá melhores ou piores, vencedores ou perdedores, mas, sim, maneiras de coexistir e buscar o apoio/empenho de todos em construir um ambiente de convivência e futuro melhor.

O movimento de economia esbarra em uma série de limitações, que envolvem falta de financiamento, preconceito e escassez de profissionais empenhados a possibilitar recursos terapêuticos e auto gestionários, com nova visão de mundo, resgate de relações familiares, vida em sociedade, ressignificação do trabalho, valorização da vida e dos produtos do esforço econômico (BARRETOS; LOPES; PAULA, 2013).

Importante lembrar que a ES busca uma distribuição justa de renda para gerar cooperação, solidariedade e valorização do manual na inserção social das mulheres no mercado de trabalho, como empreendedoras e construtoras do próprio espaço, em consonância com o apoio de familiares e demais mulheres na mesma condição financeira e biopsicosocioespiritual, principalmente frente a uma sociedade individualista, capitalista, imersa nos paradigmas e estigmatização de grupos vulneráveis.

\section{Considerações finais}

Diante do exposto, leva-se em consideração a relação entre o sexo feminino, o consumo de crack e os seus questionamentos e reflexões sobre o modo como se manifesta. Historicamente, a condição feminina favorece julgamentos e questionamentos sobre os padrões de comportamento socialmente aceitos e preconizados pelas normas culturais.

O presente estudo objetivou um olhar voltado ao resgate da mulher e sua qualidade de vida que, muitas vezes, são mal interpretadas no meio social. Em virtude dos fatos vivenciados, pode-se perceber que tais mulheres tiveram os mais variados motivos para o início e continuidade do uso de crack, verificando as condições de suas vidas, vulnerabilidade e suscetibilidade a que foram expostas, tais como perdas afetivas e familiares, relação com os filhos, inserção na prostituição e sistema prisional, viver em situação de rua e o traficar são exemplos de situações apresentadas. Após os relatos, foram traçadas abordagens para a recuperação biopsicossocial, por meio de dinâmicas, rodas de conversa, cultura de paz e oficinas de produção que proporcionassem uma renda extra e uma ressignificação, como propagadoras de sonhos.

Levar formas de independência e de reforço financeiro para ajudar na manutenção das despesas e na ocupação do tempo livre que as mulheres cumprem dentro dos lares, enquanto 
marido e filhos não estão junto a elas, proporcionou maneiras de terapia ocupacional que gerassem lucros e ocupação da mente para instaurar benefícios à saúde física, psicológica, pessoal e familiar.

As mulheres do projeto não necessitavam somente de uma ajuda para abandono do uso de substâncias, mas também de um agir diferente, para além das portas do serviço de apoio, pois precisavam encontrar-se enquanto protagonistas sociais.

Perceber a fragilidade em que os familiares se encontravam, compreender suas histórias e perspectivas de vida, gerar e descobrir saberes e estabelecer que os preconceitos vivenciados não as tornam diferentes, mas fortalecidas pelo espírito de mudança, fundamentam a relevância deste relato de experiência, visto que a extensão e a promoção da saúde para a formação profissional fortifica a integração e confiança depositadas pelo serviço durante os encontros, as vivências compartilhadas, as emoções e a receptividade das usuárias. Ademais, os momentos proporcionaram compartilhamento de experiências e enriquecimento pessoal para os acadêmicos e as integrantes do serviço.

\section{Referências}

ALVAREZ, A.P.E.; NEVES, C.E.A.B.; SILVA, C.O da. Saúde mental e economia solidária: pesquisa cartográfica em um Dispositivo clínico-político. Cadernos Brasileiros de Saúde Mental, Florianópolis, v.9, n. 22, p.124-144, 2017. Disponível em: https://www.arca.fiocruz.br/bitstream/icict/21096/2/Artigo $\% 20$ saude $\% 20$ mental $\% 20 \mathrm{e} \% 20 \mathrm{e}$ cosol\%20ariadna.pdf. Acesso em: 22 ago. 2020.

BARRETO, R. de O.; LOPES, F.T.; PAULA, A. P. P de. A economia solidária na inclusão social de usuários de álcool e outras drogas: reflexões a partir da análise de experiências em Minas Gerais e São Paulo. Cadernos de Psicologia Social do Trabalho, São Paulo, v. 16, n. 1, p. 41-56, 2013. Disponível em: http://pepsic.bvsalud.org/pdf/cpst/v16n1/a05v16n1.pdf. Acesso em: 4 maio 2020.

BELOTTI, M.; FRAGA, H. L.; BELOTTI, L. Família e atenção psicossocial: o cuidado à pessoa que faz uso abusivo de álcool e outras drogas. Caderno Brasileiro de Terapia Ocupacional, São Carlos, v. 25, n. 3, p. 617-625, 2017. DOI: http://dx.doi.org/ 10.4322/2526-8910.ctoAR0988. Acesso em: 6 jul. 2020.

CAMARGO, P. de O. et al. O enfrentamento do estigma vivido por mulheres/mães usuárias de crack. Revista Eletrônica de Saúde Mental, Álcool e Drogas, Ribeirão Preto, v. 14, n. 4, out./dez. 2018. Acesso em: 6 jul. 2020. DOI: https://doi.org/10.11606/issn.1806$\underline{6976 . s m a d .2018 .000354}$ 
CAMARGO, P. O. et al. Acompanhamento de crianças filhas de mulheres usuárias de drogas: um relato de experiência. Pesquisas e Práticas Psicossociais, São João del-Rei, v. 14, n. 2, abr./jun. 2019. Disponível em: http://pepsic.bvsalud.org/pdf/ppp/v14n2/04.pdf. Acesso em: 5 maio 2020.

CAVALGANTE, B.L. de L.; LIMA, T.S de. Relato de experiência de uma estudante de Enfermagem em um consultório especializado em tratamento de feridas. Journal of Nursing and Health, Pelotas, v. 1, n. 2, p. 94-103, jan./jun. 2012.

FERTIG, A. et al. Mulheres usuárias de crack: Conhecendo suas histórias de vida. Escola Anna Nery, Rio de Janeiro, v.20, n. 2, abr./jun. 2016. DOI https://doi.org/10.5935/14148145.20160042. Acesso em: 4 maio 2020.

FUNDAÇÃO OSWALDO CRUZ - FIOCRUZ. Estimativa do número de usuários de crack e/ou similares nas Capitais do País. Rio de Janeiro, 2013. Disponível em: https://portal.fiocruz.br/noticia/maior-pesquisa-sobre-crack-ja-feita-no-mundo-mostra-operfil-do-consumo-no-brasil. Acesso em: 4 maio 2020.

GALVES, F. R. et al. Trabalho e geração de renda como produção de cidadania na saúde mental: a experiência do núcleo de oficinas e trabalho de campinas. Cadernos Brasileiros de Saúde Mental, Florianópolis, v.8, n.18, p.206-213, 2016. Disponível em: https://periodicos.ufsc.br/index.php/cbsm/article/view/69277/41587. Acesso em: 5 maio 2020.

GONÇALVES, T.J.T.; SOBRINHO, A.M. Economia Solidária: um caminho para geração de renda e inclusão social. Revista do Programa de Pós-Graduação em Geografia, Maringá, v.3, n. 2, p. 100-24, 2011.

LACCHINI, A. J. B. Família de usuários de crack: vivências da assistência em um centro de atenção psicossocial. Tese (Doutorado em Enfermagem) - Universidade Federal do Rio Grande do Sul. Porto Alegre, 2014. Disponível em: https://www.lume.ufrgs.br/bitstream/ handle/10183/108472/000948967.pdf?sequence=1\&isAllowed=y. Acesso em: 5 maio 2020.

LUSSI, I. A. de O.; MATSUKURA, T. S.; HAHN, M. S. Reabilitação psicossocial: oficinas de geração de renda no contexto da saúde mental. O Mundo da Saúde, São Paulo, v. 35, n. 2, p. 185-192, 2011. Disponível em: https://bvsms.saude.gov.br/bvs/artigos/reabilitacao psicossocial_oficinas_geracao_renda_saude_mental.pdf. Acesso em: 5 maio 2020.

MARQUES, A.C.P.R. et al. Abuso e dependência: crack. Revista da Associação Medicina Brasileira, v. 58, n. 2, p 141-53, 2012.

MAZARO, L. M.; MATSUKURA, T. S.; LUSSI, I. A. O. Solidarity economy as a social inclusion strategy through work in the field of mental health: national overview. Cadernos 
Brasileiros de Terapia Ocupacional, v. 28, n. 1, p. 127-146, 2020. DOI https://doi.org/ 10.4322/2526-8910.ctoAO1880. Acesso em: 28 ago. 2020.

PINHO, K.L.R. et al. Relato de experiências em Inclusão Social pelo Trabalho na Saúde. São Carlos: Compacta Gráfica e Editora, 2014.

ROCHA, S.P. et al. A curricularização da extensão na graduação em saúde: a experiência de um curso de Enfermagem. Saúde em Redes, v. 5, n. 3, p. 275-283, 2019. DOI: http://dx.doi.org/10.18310/2446-4813.2019v5n3p275-283. Acesso em: 4 maio 2020.

SILVA, E. B. de O.; PEREIRA, A. L. de F.; PENNA, L. H. G. Estereótipos de gênero no cuidado psicossocial das usuárias de cocaína e crack. Cadernos de Saúde Pública, Rio de Janeiro, v. 34, n. 5, maio 2018. DOI: http://dx.doi.org/10.1590/0102-311X00110317. Acesso em: 5 maio 2020.

TEIXEIRA, M.B.; ENGSTROM, E.M.; RIBEIRO, J.M. Revisão sistemática da literatura sobre crack: análise do seu uso prejudicial nas dimensões individual e contextual. Saúde Debate, Rio de Janeiro, v. 41, n. 112, p.311-330, jan./mar. 2017. DOI: 10.1590/01031104201711225. Acesso em: 4 maio 2020.

VOLZ, P.M. et al. A inclusão social pelo trabalho no processo de minimização do estigma social pela doença. Revista Saúde e Sociedade, São Paulo, v. 24, n. 3, p. 877-886, 2015. DOI 10.1590/S0104-12902015130040. Acesso em: 6 jul. 2020. 